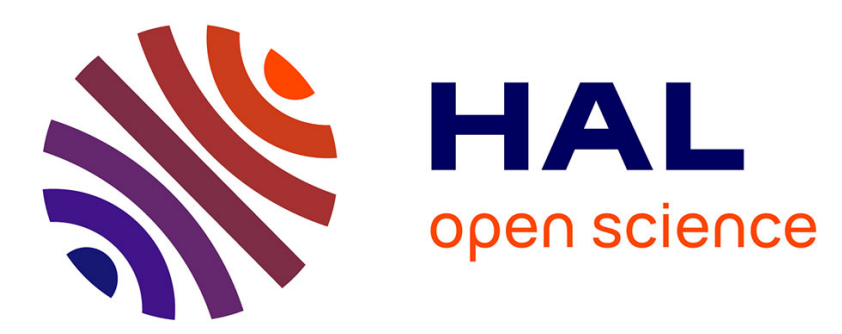

\title{
A computational study of the effects of ancillary ligands on copper(I)-ethylene interaction
}

\author{
Stéphanie Halbert, Hélène Gérard
}

\section{To cite this version:}

Stéphanie Halbert, Hélène Gérard. A computational study of the effects of ancillary ligands on copper(I)-ethylene interaction. New Journal of Chemistry, 2015, 39 (7), pp.5410-5419. 10.1039/C5NJ00546A . hal-01176228

\section{HAL Id: hal-01176228 https://hal.sorbonne-universite.fr/hal-01176228}

Submitted on 15 Jul 2015

HAL is a multi-disciplinary open access archive for the deposit and dissemination of scientific research documents, whether they are published or not. The documents may come from teaching and research institutions in France or abroad, or from public or private research centers.
L'archive ouverte pluridisciplinaire HAL, est destinée au dépôt et à la diffusion de documents scientifiques de niveau recherche, publiés ou non, émanant des établissements d'enseignement et de recherche français ou étrangers, des laboratoires publics ou privés. 


\title{
Computational study of the effects of the ancillary ligands on Copper(I)- ethylene interaction.
}

\author{
Stéphanie Halbert ${ }^{\mathrm{a}, \mathrm{b} *}$ and Hélène Gérard, ${ }^{\mathrm{a}, \mathrm{b}}$
}

${ }_{5}$ A set of $\left[\mathrm{Cu}^{(\mathrm{I})} \mathrm{L}_{\mathrm{n}}\left(\mathrm{C}_{2} \mathrm{H}_{4}\right)\right]^{\mathrm{q}}(\mathrm{q}=-1,0$, or 1$)$ complexes modelling systems of experimental interest were studied by DFT calculations to analyze the $\mathrm{Cu}^{(\mathrm{I})}$-ethylene bonding using NBO and CDA analyses. All complexes are better viewed as donor-acceptor complexes between a d ${ }^{10} \mathrm{Cu}^{(\mathrm{I})}$ center and ethylene. Backdonation depends significantly on the nature and number of the ancillary ligands, hence on the coordination sphere at copper. Back-donation is shown to vary more with the nature of the ligands than 10 donation and to increase significantly with the number of ancillary ligands. However, even with strongly donating ligands such as alkyl (modelled by $\mathrm{CH}_{3}$ ), there is no tendency of forming a metallacyclopropane. This can lead to reconsider the mechanisms of alkylation of olefin catalyzed by copper complexes.

\section{Introduction}

15 Formation of complexes between $\mathrm{Cu}^{(\mathrm{I})}$ and unsaturated substrates $\mathrm{S}$ is essential in organic synthesis since it is postulated in numerous stoichiometric and catalytic reactions. ${ }^{[1-4]}$ It is proposed to be essential for the activation and functionalization of unsaturated species. Alkene complexes have been isolated and 20 structurally characterized. ${ }^{[5]}$ A $\pi$-complex between the $\mathrm{Cu}^{(\mathrm{I})}$ fragment and $\mathrm{S}$ can be described by the Dewar-Chatt-Duncanson (DCD) model, i.e. involving donation of the $\pi$-bond of the organic moiety to a vacant metal orbital and back-donation from an occupied metal orbital to a low-lying empty $\pi^{*}$ orbital of the 25 substrate. ${ }^{[6]}$ In the case of copper(I), which has a full $\mathrm{d}^{10}$ configuration, donation can only take place to the empty $4 \mathrm{~s}$ and $4 p$ orbitals of $\mathrm{Cu}^{(\mathrm{I})}$, and thus essentially to the former since the $4 p$ are higher in energy. Back-donation, which occurs from the highest occupied d orbital, delocalizes the metal density on the $\pi^{*}$ 30 orbital of the substrate resulting, at the limit, in a formal oxidation of $\mathrm{Cu}^{(\mathrm{I})}$ to $\mathrm{Cu}^{(\mathrm{III})}$. The $\pi$-complex is then viewed as a metallacyclopropane. ${ }^{[7]}$ As such, the interaction of a multiple bond with copper is commonly considered as an oxidative addition. ${ }^{[8]}$ Early computational studies of the coordination of $\pi$ 35 ligands with $\mathrm{Cu}^{(\mathrm{I})}$ species highlighted the formation of $\mathrm{Cu}^{\text {(III) }}$ complexes on the basis of structural parameters of the $\mathrm{Cu}-\mathrm{CC}$ moiety in a limited number of systems. ${ }^{[4,9-10]}$ The formation of

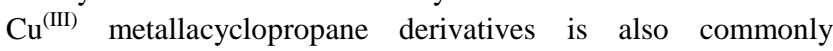
considered when discussing experimental results, in particular for 40 the reaction of alkylation of olefin catalyzed by copper complexes. Several analyses of the bonding scheme in specific $\mathrm{Cu}^{(\mathrm{I})}$ complexes (with ethylene as substrate) were reported. ${ }^{[11-14]}$ Nevertheless, no systematic study on a large panel of structures was reported.

${ }_{45}$ In this work, we aim at evaluating in which cases and to which extend the coordination of $\mathrm{Cu}^{(\mathrm{I})}$ to an unsaturated ligand can be considered as an oxidative addition. For this purpose, we consider a large representative set of $\mathrm{Cu}$-ethylene complexes with different total charge, ancillary ligands and coordination spheres.
${ }_{50}$ Calculations of these complexes and systematic use of electron density analysis tools allow to better assign the bonding between $\mathrm{Cu}$ and the substrate. This study participates also to the need of developing a quantitative structure/property relationship for this family of complexes. This is the first attempt to build a ligand

55 knowledge base for $\mathrm{Cu}$ complexes following previous studies for different metals and ligand sets. ${ }^{[15-19]}$

\section{Results}

Models. A set of twenty cationic, anionic or neutral ethylene $\mathrm{Cu}$ complexes, with monodentate or bidentate L- or X-type ligands 60 (phosphine, carbene, alkyl or heteroalkyl, halide ...) was selected (see Scheme 1 where ancillary ligands are organized according to charge). The study focuses on the interaction between ethylene and the $\mathrm{Cu}$ moieties. Complex $\mathbf{1}$, in which ethylene is coordinated to a naked $\mathrm{Cu}^{(\mathrm{I})}$ cation, is the simplest system. Generic ligands 65 either neutral like $\mathrm{PH}_{3}$ or monoanionic like $\mathrm{CH}_{3}, \mathrm{~F}, \mathrm{Cl}, \mathrm{Br}, \mathrm{OCH}_{3}$, and $\mathrm{CN}$ were selected. Related ligands of synthetic interest in catalytic copper chemistry were also used. N-heterocyclic carbenes (NHC) with unsaturated or saturated carbon backbones are introduced as in $\mathbf{2 - 3}, \mathbf{1 3 - 1 4}, \mathbf{1 6 - 1 7}$ and 25-26. ${ }^{[20]}$ Complexes 2 70 and $\mathbf{3}$ carry the simplest NHC ligands. Complexes $\mathbf{1 6}$ and $\mathbf{1 7}$ are models of systems developed in catalytic asymmetric alkylation by Mauduit et al. ${ }^{[21]}$ Complexes 13-14 and 25-26 are alkylated forms of 2-3 and 16-17. These alkylated complexes are proposed as intermediate during the catalytic cycles. ${ }^{[22]}$ Mono- and bi75 phosphine ligands of experimental interest were considered: they include BINAP (6) (BINAP: 2,2'-bis(diphenylphosphino)-1,1'binaphthyl) ${ }^{[23]}$ and DiPPAM (18) (DIPPAM: DiPhenylPhosphinoAzoMethinylate). ${ }^{[24]}$ These complexes are also examined in their native and alkylated forms. The structure 80 of these $\mathrm{Cu}$-ethylene complexes was computed (see Computational details), the bond dissociation energy of ethylene from these complexes was determined, and several correlations between structural features and electronic properties (in particular associated with the electron density transfer between $\mathrm{Cu}$ and 
ethylene) were analysed.
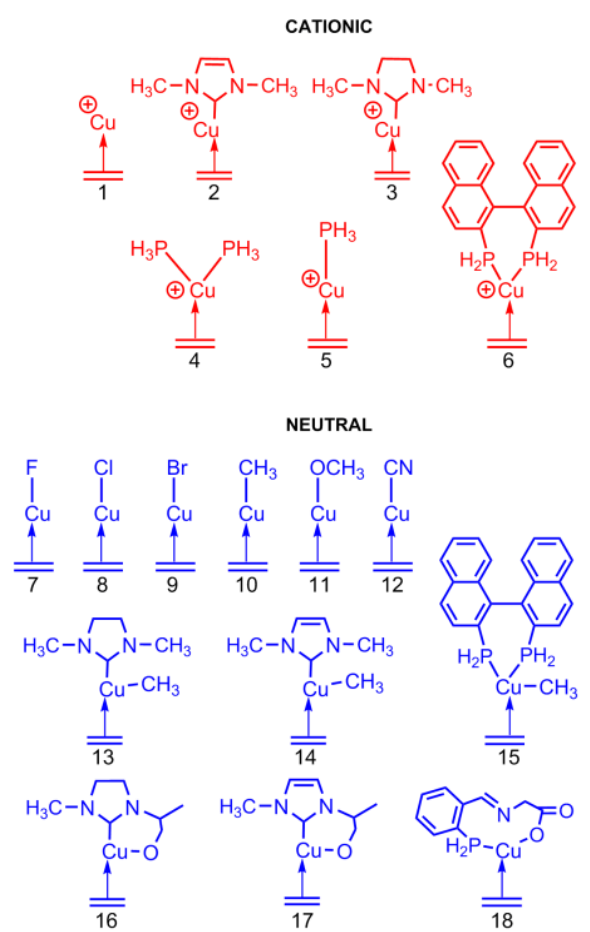

ANIONIC
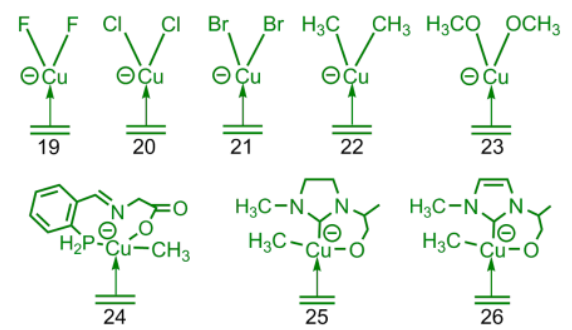

Scheme 1 Schematic representation of ethylene complexes (color code refers to the total charge of complexes. Red: cationic; Blue: neutral;

Green: anionic).

${ }_{5}$ Geometries. The geometry of the complexes shown in Scheme 1 was optimized and selected parameters, associated with the coordinated ethylene are shown in Table 1 . We define $\langle\mathrm{Cu}-\mathrm{C}\rangle$ as the average of the two $\mathrm{Cu}-\mathrm{C}$ distances and the average $\mathrm{HHCC}$ dihedral angle $\left(180^{\circ}\right.$ in free ethylene and $120^{\circ}$ in a pure $\mathrm{sp}^{3}$ 10 carbon) as a measure of the non planarity of coordinated ethylene.

The coordination mode at the metal (described by considering ethylene as a single ligand) depends on the denticity of the ancillary ligands (see Fig. 1). The $\mathrm{n}=1$ complexes have the 15 expected structure with ethylene coordinated trans to L (the L$\mathrm{Cu}$-ethylene centroid angle is close to $180^{\circ}$ ). The $\mathrm{n}=2$ complexes have the two ancillary ligands, the metal and the two ethylene carbon atoms in a plane. This forms a trigonal planar geometry if ethylene is viewed as a single neutral ligand and a square planar 20 geometry if ethylene is viewed as a bidentate $X_{2}$ ligand (Fig. 1, 22 and 16). For $\mathrm{n}=3$, where a methyl group is always present, a trigonal based pyramid is obtained (considering ethylene as a neutral ligand). In all cases, the ethylene and the $\mathrm{CH}_{3}$ group occupy two basal sites while the apical site is occupied by the 25 weakest $\sigma$-donor, namely the alcoholate arm (pointing toward the back in Fig. 1, in 25 and 26), or the carboxylate arm (in 24), or one of the two phosphines in $\mathbf{1 5}$ (thus leading to unequal $\mathrm{Cu}$ phosphine distances (2.470 vs $2.304 \AA$ ).
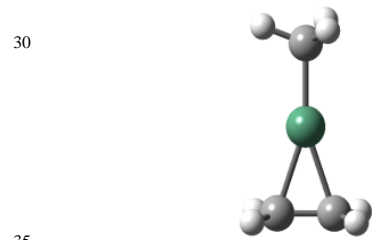

10

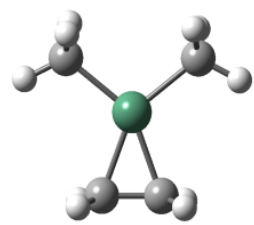

22

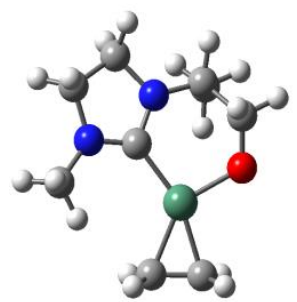

16

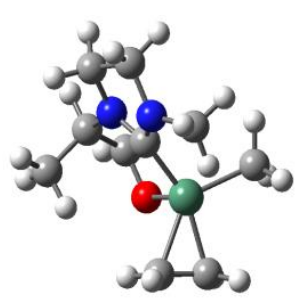

25
45

Fig. 1 Geometries of ethylene-Cu complexes depending on the denticity for $n=1(\mathbf{1 0}), n=2(\mathbf{2 2}$ and $\mathbf{1 6})$ and $n=3(\mathbf{2 5})$.

The $\left[\mathrm{Cu}\left(\mathrm{C}_{2} \mathrm{H}_{4}\right)\right]^{+}$complex has $\langle\mathrm{Cu}-\mathrm{C}\rangle$ and $\mathrm{C}=\mathrm{C}$ bond distances 50 of 2.045 and $1.395 \AA$, respectively, which agree with previous theoretical studies. ${ }^{[11,13,25]}$ The calculated $\mathrm{C}=\mathrm{C}$ bond distance of $1.388 \AA$ in $\left[\mathrm{CuCl}\left(\mathrm{C}_{2} \mathrm{H}_{4}\right)\right]$ is also in good agreement with a recent theoretical and experimental study. ${ }^{[26]}$ For the structures that have been considered, the $\mathrm{C}=\mathrm{C}$ distances range from $1.375 \AA$ in $\mathbf{3}$ 55 (saturated NHC ligand) to $1.428 \AA$ in $\left[\mathrm{Cu}\left(\mathrm{CH}_{3}\right)_{2}\left(\mathrm{C}_{2} \mathrm{H}_{4}\right)\right]^{-}(\mathbf{2 2})$. Thus, as expected, the $\mathrm{C}=\mathrm{C}$ bond distance is longer for all complexes than the value of $1.341 \AA$ calculated at the same computational level in free ethylene.

Strong pyramidalization of the carbon of the ethylene ligand is ${ }_{60}$ characteristic of a metallacyclopropane. A study by Morokuma et $a l .{ }^{[27]}$ and an analysis by Uddin et al. ${ }^{[28]}$ have used an alkene with steric strain to define a reference of a metallacyclopropane (Pt in their study). We thus selected complex 27 (Scheme 2) to complete the study. The calculated distance of $1.453 \AA$ for the ${ }_{65} \mathrm{CC}$ bond in $\mathbf{2 7}$, which is longer that in all other complexes, can serve as upper limit, whereas full $\mathrm{sp}^{3}$ hybridation is ensured by the strained pyramidalization $\left(120^{\circ}\right.$ in 27). In comparison, complexes 1-26 are significantly closer to planar ethylene, as evidenced in Fig. 1. This can be quantified by the HHCC dihedral 70 angle averaged over the two ends of ethylene whose values vary from $169.8^{\circ}$ to $158.3^{\circ}$ for complexes 1-26. A correct linear correlation $\left(\mathrm{R}^{2}=0.83\right)$ is obtained between the HHCC dihedral angle and the $\mathrm{C}=\mathrm{C}$ bond elongation with small values of $\mathrm{HHCC}$ being associated with long CC bond (See Supporting 75 Information). 


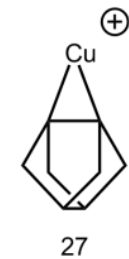

Scheme 2 Schematic representation of the strained olefin complex to copper(I), used as a reference for metallacyclopropane.

The $\mathrm{C}=\mathrm{C}$ distance depends on the total charge of the complex as already proposed by Frenking et al. for copper-acetylene 5 complex. ${ }^{[25 \mathrm{~d}]}$ In the $\mathbf{1 - 2 6}$ set, the $\mathrm{C}=\mathrm{C}$ bond distance of $1.382 \AA$ obtained by averaging over the cationic complexes is shorter than that of $1.394 \AA$ for the neutral complexes, which is itself shorter than that of $1.406 \AA$ for the anionic systems. In others words the metallacycle character of the $\mathrm{C}=\mathrm{C}$ coordination increases from 10 cationic to anionic complexes. In contrast, there is no apparent correlation between the $\mathrm{C}=\mathrm{C}$ bond distance and the denticity of the ancillary ligands. For instance, for the structures with $n=3$, the average $\mathrm{C}=\mathrm{C}$ bond distance is $1.397 \AA$. This value is smaller than that for $\mathrm{n}=2$ ligands $(1.404 \AA)$ but longer than that for $\mathrm{n}=1$ $15(1.383 \AA$ ) . No trend involving the coordination number could be established.

In general, one considers that the $\mathrm{Cu}-\mathrm{C}$ bond distance decreases when the $\mathrm{C}=\mathrm{C}$ bond distance increases (from olefin complexes to metallacyclopropanes) if no other factor intervenes. In the present 20 case, this correlation between the $\langle\mathrm{Cu}-\mathrm{C}\rangle$ and $\mathrm{C}=\mathrm{C}$ bond distances is not simple. A rough correlation can be found for a set of ligands of a given denticity (see Supporting Information for graphical information), for which a given range of $\mathrm{Cu}-\mathrm{C}$ bond distances is observed. Nevertheless, these ranges overlap and, for ${ }_{25}$ given denticity (see for instance $\mathrm{n}=2$ ), strong $\sigma$-donating groups like methyl or carbene (for instance complexes 13, 14 and 22) do not fit the behaviour of the other complexes as they lengthen the $\mathrm{Cu}-\mathrm{C}$ bonds to which they are essentially transoid.

${ }_{30}$ Energetics. The ethylene bond dissociation energy $\left(D_{\mathrm{e}}\right)$, the interaction energy (IE) and the deformation energy (Def which is the sum of the deformation energies of the two fragments $\left[\mathrm{CuL}_{n}\right]$ and ethylene) energies are given in Table 1 for all complexes. The bond dissociation energy $\mathrm{D}_{\mathrm{e}}$, calculated with respect to the 35 energies of the relaxed fragments can be decomposed in the deformation energy (Def) and the interaction energy (IE). Def evaluates the energy cost to bring each fragment from its optimized structure as an isolated species to that in the complex. The interaction energy (IE) is that between fragments in the 40 structures they have in the complexes. For convenience, we will usually discuss the absolute values of IE, |IE|, large absolute value of IE being associated with large stabilizing interaction energy. The bond dissociation energy is related to $|\mathrm{IE}|$ and Def as shown in eq 1 (all values being positive in this definition).

45

$\mathrm{D}_{\mathrm{e}}=|\mathrm{IE}|+$ Def

The $\mathrm{D}_{\mathrm{e}}$ energy of $45.6 \mathrm{kcal} / \mathrm{mol}$ calculated for $\left[\mathrm{CuF}\left(\mathrm{C}_{2} \mathrm{H}_{4}\right)\right](7)$ is similar to the value of $38.6 \mathrm{kcal} / \mathrm{mol}$, previously reported. ${ }^{[12]}$ For $50 \mathrm{n}>0$ complexes, the bond dissociation energy ranges from 1.6 (22) to $45.6 \mathrm{kcal} / \mathrm{mol}$ (7). These values can be divided in three groups determined by the total charge of the complex. The cationic complexes have $D_{e}$ averaging at $43.9 \mathrm{kcal} / \mathrm{mol}$ for complexes (2-6). Neutral complexes have lower $\mathrm{D}_{\mathrm{e}}$ averaging at ${ }_{55} 25.9 \mathrm{kcal} / \mathrm{mol}(\mathbf{7 - 1 8})$, and anionic complexes have the lowest $\mathrm{D}_{\mathrm{e}}$ (averaging at $4.3 \mathrm{kcal} / \mathrm{mol}$ for 19-26). This is in line with the important electrostatic contribution to the binding highlighted for $\left[\mathrm{Cu}\left(\mathrm{C}_{2} \mathrm{H}_{4}\right)\right]^{+}$. ${ }^{[11]}$

The large range of $D_{e}$ values is associated with a large range of ${ }_{60}$ deformation energy. Large Def energies are associated with small values of $D_{e}$. For instance, $D_{e}$ of less than $10 \mathrm{kcal} / \mathrm{mol}$ (between 1.6 and $9.1 \mathrm{kcal} / \mathrm{mol}$ ) is associated with Def larger than 18 $\mathrm{kcal} / \mathrm{mol}$ (between 18.5 and $42.7 \mathrm{kcal} / \mathrm{mol}$ ). Remarkably, Def for the $\left[\mathrm{CuL}_{\mathrm{n}}\right]$ moiety can reach values as high as $32.9 \mathrm{kcal} \mathrm{mol}^{-1}$ (in ${ }_{65} 22$ ) while Def for ethylene varies over a more limited energy range (upper limit of $9.8 \mathrm{kcal} \mathrm{mol}^{-1}$ in 22). Large deformation energies within the metal fragment has been mentioned previously for $\mathrm{Cu}^{(\mathrm{I})}$ complexes. ${ }^{[29]}$

The range of the absolute values of IE, $|\mathrm{IE}|$, is significantly 70 smaller with values between 26.0 and $50.2 \mathrm{kcal} / \mathrm{mol}$, for $\mathbf{2 4}$ and $\mathbf{7}$, respectively ( $\mathbf{1}$ and $\mathbf{2 7}$ are not included), compared with the corresponding ranges of values for $\mathrm{D}_{\mathrm{e}}(3.9$ to $45.6 \mathrm{kcal} / \mathrm{mol})$. The largest value of $|\mathrm{IE}|(71.1 \mathrm{kcal} / \mathrm{mol})$ in 27 , highlights the role of strain in increasing the interaction energy. ${ }^{[28]}$

75

Electronic properties. A tempting way to evaluate the " $\mathrm{Cu}$ (III), character of a complex would be to consider the charge on the copper centre (see Table 1). As expected, the charges on $\mathrm{Cu}$ are significantly less than the formal charge of +3 . However, this is 80 not a valid criteria since it is well recognized that "charges" and "oxidation state" have no reason to be identical. ${ }^{[31]}$ Nevertheless, the computed charge on copper(I) atom is reported to be much less than $+1,{ }^{[4]}$ while it may be just around +1 for $\mathrm{Cu}^{(\mathrm{III})} \cdot{ }^{[30]}$ In the set of complexes of Scheme 1 the Natural Population analysis 85 (NPA) charge at $\mathrm{Cu}$ ranges from 0.623 in $\mathbf{1 0}$ to 1.097 in $\mathbf{1 9}$. The charge is 0.779 in $\mathbf{2 7}$, which is viewed as a reference model for $\mathrm{Cu}^{\text {(III) }}$ metallocyclopropane, and higher (0.871) in $\mathbf{1}$, which has no ancillary ligand and no strain. Therefore, charge at $\mathrm{Cu}$ cannot be used as a significant reporter.

90 We next considered properties associated with the electron transfer between $\left[\mathrm{CuL}_{\mathrm{n}}\right]$ and ethylene as analyzed by the Natural Bond Orbital (NBO) and the Charge Decomposition Analysis (CDA). The NBO analysis provides a description of chemical species in term of Lewis structures through covalent bonds and 95 donor-acceptor interactions. ${ }^{[32]}$ The NBO analysis of donation and back-donation, between phenanthroline copper complexes and ethylene was previously used. ${ }^{[13]}$ The CDA method of Frenking et al constructs the wave function of the complex in term of linear combination of donor and acceptor orbitals (See 100 computational details for further information). These two methods are currently used to analyze interactions between chemical fragments (here $\left[\mathrm{CuL}_{n}\right]$ and ethylene). They analyze the wave functions in different ways. In particular, NBO uses a localization procedure while CDA uses canonical orbitals. It is 105 thus of interest to discuss the analogies and differences that emerge from these two methods.

Copper, which is a $3 \mathrm{~d}$ transition metal has only its $4 \mathrm{~s}$ orbital for establishing covalent bonding since its $3 \mathrm{~d}$ shell is fully occupied and since its $4 \mathrm{p}$ shell is considered as unable to provide covalent 
bonds as shown by Weinhold and Landis. ${ }^{[32]}$ The NBO supports this proposal for all systems, 1-27. The covalent bond with copper involves the ancillary ligands $L$ (for $n=1$ ). For $n=2$ and higher, the situation is slightly more complicated and the $4 \mathrm{~s}$ 5 orbital appears to be involved in donor-acceptor interactions with all ligands. The key point for this study is that in none of the complexes a covalent $\mathrm{Cu}-\mathrm{C}$ bond is formed between the metal and ethylene, as it would be expected in a metallacyclopropane form. All complexes are formed by donor-acceptor interactions 10 between neutral ethylene and $\mathrm{a}\left[\mathrm{CuL}_{\mathrm{n}}\right]$ fragment carrying the total charge of the complex. This also means that in this donor (ethylene)-acceptor $\left(\left[\mathrm{CuL}_{n}\right]\right)$ interaction, the accepting orbitals on the metal side are the $\sigma^{*}(\mathrm{CuL})$ orbitals $(\omega$ bond following the NBO terminology).

15 The CDA analysis of these ethylene complexes carried out using ethylene and $\left[\mathrm{CuL}_{n}\right]$ as fragments, provided the following terms: (i) the donation from ethylene to $\left[\mathrm{CuL}_{n}\right]$ (term $\mathrm{d}$ in Table 2), (ii) the back-donation from $\left[\mathrm{CuL}_{n}\right]$ to ethylene (term $b$ in Table 2) (iii) the repulsion associated with the interaction between the 20 occupied orbitals of the two fragments (term $r$ in Table 2). The appropriateness of this analysis is established when the sum of these densities is equal to the total density and the residual term $\Delta$, close to zero (See computational details for further details). Indeed, this residual term is small for the entire set 1-27. This 25 feature is a characteristic of species that can be viewed as donoracceptor complexes.

$\mathrm{NBO}$ and CDA analyses confirm the $\mathrm{Cu}$ retains a $\mathrm{d}^{10}$ electronic structure in all complexes with a maximum of 0.7 e transferred to ethylene. They also consider that binding between ethylene and $30\left[\mathrm{CuL}_{n}\right]$ is of the type donor-acceptor and follows the DewarChatt-Duncanson model. ${ }^{[28]}$ This is even the binding description found for $\mathbf{2 7}$, which is poorly compatible with a $\mathrm{Cu}^{\text {(III) }}$ complex. NBO results can be further analyzed by quantifying the electron population of ethylene $\pi$ and $\pi^{*}$ (Table 1). The NBO electron 35 occupancies of the $\pi$ orbital range from $1.733 \mathrm{e}$ in $\mathbf{1}$ to $1.902 \mathrm{e}$ in 26 indicating that 0.267 to 0.098 e are donated from $\pi$ orbital to $\mathrm{Cu}$ fragment. These values are smaller than that in $\mathbf{2 7}$ for which the ethylene $\pi$ gives 0.396 e. The complexes with phosphine ligands are associated with larger $\pi$-ethylene $\rightarrow \mathrm{Cu}$ donation $40(0.152,0.192,0.155$, and 0.127 e in $\mathbf{4 , 5 , 6}$ and $\mathbf{1 8}$, respectively), which is consistent with an electron withdrawing behavior of these phosphine ligands. Back-donation into the ethylene $\pi^{*}$ orbital, are fluctuating over a larger scale: 0.103 e in $\mathbf{5}$ and 0.652 in 22. To be noted the electron occupancy of $\pi^{*}$ in the strained 45 olefin complex 27 is not the highest in the whole series as it would be expected if it was a metallacyclopropane. In fact, it has an intermediate value of 0.392 e. Back-donation thus appears to vary more (by a factor of 5) than donation (by a factor of less than 2) with the nature of the complex. This agrees with previous 50 results that donation is less sensitive to ligand variation as shown on a series of ethylene copper complexes with polydentate ancillary ligands (bipyridine, ....). ${ }^{[14]}$ In general, back-donation is larger for the anionic systems (averaging around $0.457 \mathrm{e}$ ) than for the neutral and cationic systems (average value of $0.271 \mathrm{e}$ ). In 55 contrast, donation is less influenced by the charge since the average value of 0.186 e for the cationic complexes is similar to that of 0.129 e for neutral and anionic systems.

Quantification of donation and back-donation is also a direct result obtained from CDA analysis (Table 2). CDA and NBO ${ }_{60}$ agree in the quantification of the back-donation part. A very good linear correlation $\left(\mathrm{R}^{2}=0.94\right)$ appears between back-donation computed with the CDA approach and the NBO $\pi^{*}$ population (see Supporting Information for a graphical representation) except for complex 27. This is due to the fact that the $\pi^{*}$ of this 65 strained olefin, is already partially occupied ( $0.138 \mathrm{e})$ in its noncoordinated state. An improved correlation is thus obtained when subtracting 0.138 e from the NBO $\pi^{*}$ population. (Supporting Information).

The NBO and CDA analyses give somewhat different 70 information on the amounts of donation. The NBO analysis showed that donation and back-donation are rather comparable in magnitude and that often the back-donation dominates (such as in 11, 13-18 and 19-26). This is not the information provided by CDA, which indicates that donation dominates significantly over 75 donation. Ratio d/b which is higher $\geq 4$ for $\mathbf{1 - 5}$, decreases to around 2 for many complexes and is not smaller than 1.4 (set 2226). These differences are most likely due to the different manners in calculating the electron transfer from either localized or canonical orbitals and may be also from the different 80 methodologies used for calculating the density (DFT vs MP2, see Computational details). These differences also involve the nature of the donating orbitals. Thus, while the DCD model usually considers that only the ethylene $\pi$ orbital donates electron density in the interaction with $\left[\mathrm{CuL}_{n}\right]$ fragment, $\mathrm{CDA}$ involves also the ${ }_{85} \mathrm{C}=\mathrm{C} \sigma$ bond in the donation. In fact, the CDA analysis for $\mathbf{1 0}$ shows that $50 \%$ of the donation is associated with the $\pi$ orbital, $36 \%$ with the $\sigma$ orbital (Fig. 2) and the $14 \%$ is spread over other ethylene orbitals. The NBO analysis does not indicate any donation of density from the $\sigma$ orbital of ethylene, which remains 90 fully occupied in all complexes. Since the orbitals are not defined in the same manner in the two methods, the electron transfers calculated by the two methods have no reasons to be identical and it is not possible to go further in this analysis.

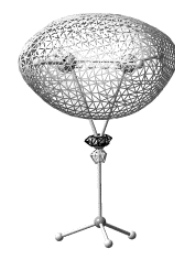

$\sigma$ orbital: $0.155 \mathrm{e}$

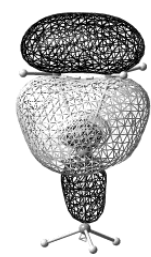

$\pi$ orbital: $0.213 \mathrm{e}$
Fig. 2 Donating orbitals (left, $\sigma \mathrm{CC}$ orbital, and right $\pi \mathrm{CC}$ orbital) according to the CDA analysis for complex $\mathbf{1 0}$.

Table 2 Charge Decomposition Analysis (d: donation, b:back-donation, $105 \mathrm{~b} / \mathrm{d}$ ratio, r: repulsive part, $\Delta$ : residual term) for olefin complexes.

\begin{tabular}{l|l|l|l|l|l} 
Entry & d & b & d/b & r & $\Delta$ \\
\hline
\end{tabular}




\begin{tabular}{c|c|c|c|c|c}
\hline $\mathbf{1}$ & 0.479 & 0.037 & 12.95 & -0.095 & -0.038 \\
$\mathbf{2}$ & 0.457 & 0.056 & 8.20 & -0.124 & -0.033 \\
$\mathbf{3}$ & 0.456 & 0.048 & 9.5 & -0.120 & -0.031 \\
$\mathbf{4}$ & 0.451 & 0.094 & 4.80 & -0.226 & -0.021 \\
$\mathbf{5}$ & 0.446 & 0.033 & 13.52 & -0.107 & -0.035 \\
$\mathbf{6}$ & 0.443 & 0.123 & 3.60 & -0.233 & -0.026 \\
\hline $\mathbf{7}$ & 0.468 & 0.168 & 2.79 & -0.157 & -0.034 \\
$\mathbf{8}$ & 0.458 & 0.109 & 4.20 & -0.171 & -0.025 \\
$\mathbf{9}$ & 0.455 & 0.103 & 4.42 & -0.172 & -0.023 \\
$\mathbf{1 0}$ & 0.427 & 0.082 & 5.21 & -0.236 & -0.013 \\
$\mathbf{1 1}$ & 0.476 & 0.168 & 2.83 & -0.186 & -0.028 \\
$\mathbf{1 2}$ & 0.422 & 0.075 & 5.63 & -0.151 & -0.024 \\
$\mathbf{1 3}$ & 0.459 & 0.259 & 1.77 & -0.337 & 0.013 \\
$\mathbf{1 4}$ & 0.452 & 0.253 & 1.79 & -0.340 & 0.015 \\
$\mathbf{1 5}$ & 0.432 & 0.207 & 2.09 & -0.345 & 0.001 \\
$\mathbf{1 6}$ & 0.468 & 0.228 & 2.05 & -0.281 & -0.007 \\
$\mathbf{1 7}$ & 0.468 & 0.232 & 2.02 & -0.277 & -0.007 \\
$\mathbf{1 8}$ & 0.424 & 0.182 & 2.33 & -0.261 & -0.013 \\
\hline $\mathbf{1 9}$ & 0.421 & 0.236 & 1.78 & -0.267 & 0.005 \\
$\mathbf{2 0}$ & 0.397 & 0.170 & 2.34 & -0.352 & 0.008 \\
$\mathbf{2 1}$ & 0.395 & 0.153 & 2.58 & -0.369 & 0.005 \\
$\mathbf{2 2}$ & 0.437 & 0.293 & 1.49 & -0.438 & 0.0371 \\
$\mathbf{2 3}$ & 0.464 & 0.267 & 1.74 & -0.293 & 0.020 \\
$\mathbf{2 4}$ & 0.392 & 0.210 & 1.87 & -0.405 & 0.012 \\
$\mathbf{2 5}$ & 0.355 & 0.250 & 1.42 & -0.391 & 0.020 \\
$\mathbf{2 6}$ & 0.357 & 0.251 & 1.42 & -0.406 & 0.023 \\
\hline $\mathbf{2 7}$ & 0.555 & 0.079 & 7.03 & -0.133 & -0.036 \\
\hline & & & & &
\end{tabular}

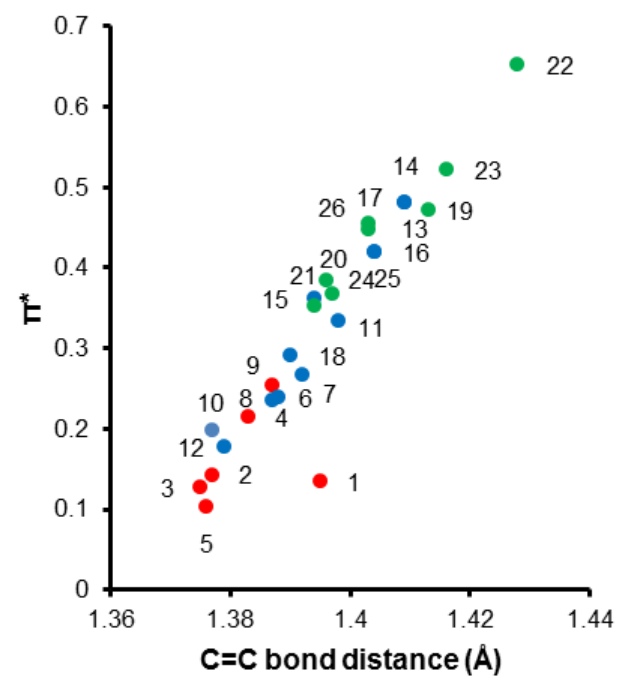

Fig. $3 \mathrm{Cu} \rightarrow$ Ethylene back-donation (NBO electron occupancy of ethylene $\pi^{*}$ ) for 1-26 as a function of the $\mathrm{C}=\mathrm{C}$ bond distance $(\AA)$ (the color code refers to the total charge of the complex. Red: cationic, Blue: neutral, Green: anionic).

${ }_{5}$ Correlations. In donor-acceptor complexes, one expects a relation between the amount of electron transfers and the energetics of the complexes. However, the sum of donation and back-donation transfers was thus plotted as a function of $\mathrm{D}_{\mathrm{e}}, \mathrm{IE}$ and Def, indicating the absence of any correlation (Supporting 10 Information). No better correlations were found using the amount of charge transfer associated with back-donation (selected because it varies the most within the set 1-27). The same result applies to the amount of donation. This generalizes the proposal that the ethylene dissociation energy, $D_{e}$, is not a measure of the ${ }_{15} \mathrm{Cu}-\mathrm{C}$ covalent interactions resulting from the donation and backdonation transfers. ${ }^{[33]}$ The electrostatic interaction between the metal fragment and ethylene appears an important factor, regardless of the total charge, even for the anionic systems.

The geometrical features appear to be correlated with the electron 20 transfer between the two fragments. A good linear correlation $\left(\mathrm{R}^{2}\right.$ $=0.90)$ is found between back-donation and the $\mathrm{C}=\mathrm{C}$ bond distance (Fig. 3). However, no correlation between the amount of donation and the $\mathrm{C}-\mathrm{C}$ bond distance could be found (Supporting Information). Thus, in these complexes where the variation back25 donation is important, the geometrical features of the coordinated ligand appear to depend more on the latter. This trend is often thought to apply to the coordination of unsaturated ligands to transition-metal complexes. ${ }^{[7]}$

\section{Discussion}

30 In Figure 3, the color code highlights that the complexes somewhat gather as function of their charge. All cationic complexes appear in the lower left corner (i.e. short CC distance and low back-donation, red in Fig. 3) whereas the anionic complexes are more on the upper right corner of the figure 35 (medium to long CC distance and medium to large backdonation, green in Fig. 3) and spread over a larger range of values since the nature and denticity of the ancillary ligands are rather diverse. The neutral complexes appear to overlap and bridge the charged species, being spread over nearly the whole range of

40 values (short to medium CC bond distances and small to medium back-donation, blue in Fig. 3).

Influence of the basicity of the $\mathrm{X}$-type ligands. Computational studies for copper-( $\kappa^{2}$-phenanthroline $)$ complexes highlighted that ${ }_{45} \mathrm{Cu} \rightarrow$ ethylene back-donation increases with the basicity of ancillary ligand. ${ }^{[13]}$ This led us to consider this argument for our set of complexes. Basicity increases in the order halide $<\mathrm{OCH}_{3}<$ alkyl. This argument accounts for the trends in the anionic complexes 19-23. The metal orbital, which is involved in the ${ }_{50}$ back-donation, is $\sigma$-antibonding with the $2 \mathrm{X}$ ligands (Fig. 4 left) and is thus hybridized towards the ethylene ligand and raised in energy with increasingly good donor (halide, alkoxy, alkyl). ${ }^{[34]}$ In contrast, the mono-ligated complexes (7-12) follow another trend since, according to the electron occupation of $\pi^{*}$ ethylene, 55 the best donor is the alkoxy, the least are the alkyl and $\mathrm{CN}$ groups, the halide groups being intermediate. The nature of the $\mathrm{d}$ orbital involving in the back-donation (Fig. 4 right) rationalizes this trend. The orbital is $\sigma$-non-bonding but is $\pi$-anti-bonding with the lone pairs of the $\mathrm{X}$ group (and thus with the alkoxy or ${ }_{60}$ the halide). This creates a 4-electron repulsion between $X$ and the $\mathrm{d}$ occupied which is known to increase the back-donation. ${ }^{[35]}$ The alkoxy group appears to be a better $\pi$ donor (probably good overlap associated with short distances and rather compact orbitals) than a halide, which accounts for the trend in this set.

${ }_{65}$ However, the amount of back-donation calculated for any member of the 7-12 set is not sufficient ( $<<1$ electron) to justify a denomination of metallacyclopropane in contrast with the proposal to consider to $\left[\mathrm{Cu}(\mathrm{F})\left(\mathrm{C}_{2} \mathrm{H}_{4}\right)\right]$ as metallacycle. ${ }^{[12]}$ 

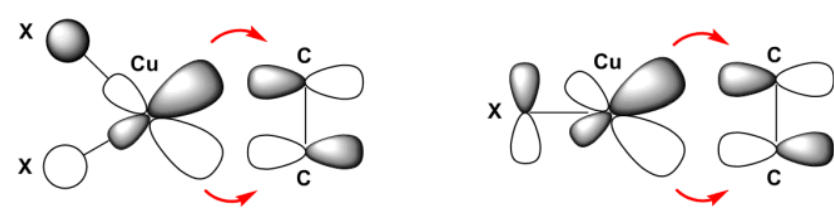

Fig. $4 \mathrm{Cu}^{(\mathrm{I})} \mathrm{d}$ orbital involved in back-donation to ethylene (left) $\mathrm{CuX}_{2}, \sigma-$ antibonding with $\mathrm{X}$, (right) $\mathrm{CuX}, \pi$-antibonding with lone pair of $\mathrm{X}$.

${ }_{5}$ NHC and phosphine ligands. NHC and phosphine ligands are ubiquitous in $\mathrm{Cu}$ complexes. For such ligands, electron-donating power has been evaluated using either $\mathrm{CO}$ stretching frequency in $\left[\mathrm{LNi}(\mathrm{CO})_{3}\right]^{[15]}$ or experimentally by $\mathrm{pK}_{\mathrm{a}}$ measurement. ${ }^{[36]} \mathrm{NHC}$ ligands are imidazolylidene with an unsaturated aromatic 10 backbone or imidazolidinylidene with a saturated backbone. These two ligands, which have similar electron-donating capability are slightly better electron donor than phosphine, but the difference is in total modest since the $\mathrm{CO}$ stretching frequencies in $\left[\mathrm{LNi}(\mathrm{CO})_{3}\right]$ are $30 \mathrm{~cm}^{-1}$ lower for $\mathrm{NHC}{ }^{[15]}$

15 In line with these studies, the two prototype NHC ligands, 2 and $\mathbf{3}$ (unsaturated and saturated NHC, respectively) lead to similar back-bonding and $\mathrm{C}-\mathrm{C}$ bond length. The results are also similar in the presence of an additional chelating alkoxy-arm (16 and 17). Comparing NHC and phosphine ligands in cationic complexes 2 20 and $\mathbf{3}$ and $\mathbf{5}\left(\mathrm{PH}_{3}\right)$, the amounts of back-donation and the $\mathrm{C}-\mathrm{C}$ bond distances are similar although marginally higher for $\mathrm{NHC}$ ligands.

Changing mono to di-coordination for phosphines (5 and $\mathbf{4}$, respectively) essentially double the back-donation (Table 1). The 25 reason has been already presented in Figure 4 where backdonation is shown to be always larger with two ancillary ligands. Complexes $\mathbf{4}$ and $\mathbf{6}$ address the influence of a chelating binaphtyl ligand simplified by replacing the phenyl substituent on phosphorus by hydrogen atoms. The present calculations, which 30 give very similar results for the amount of back-donation and C-C bond distances, suggest that two monodentate phosphine and the chelating BINAP lead to similar $\mathrm{Cu}$-ethylene complex. One should however not conclude that these two complexes would behave in similar ways in the catalytic reactions involving 35 systems like $\mathbf{4}$ and $\mathbf{6}$.

Another way to increase the coordination number at copper is illustrated in the $(\mathbf{2}, \mathbf{3})$ and $(\mathbf{1 6}, \mathbf{1 7})$ set. The two first complexes are monodentate NHC ethylene complexes while the two latter have an additional alkoxy arm. For the same reasons as before, 40 the back-donation is larger (by about a factor of 2.5) in $(\mathbf{1 6}, \mathbf{1 7})$ than in $(\mathbf{2}, \mathbf{3})$. To be noted the coordination of an anionic ligand to form a neutral complex (16 or 17) from a cationic reactant (2 or 3) increases more the back-donation than adding a neutral ligand that does not modify the total charge (compare 5 and 4).

${ }_{45}$ Furthermore, as could be expected, coordination of a stabilized anion ligand like the carboxylate in the DiPPAM complex 18 increases much less the back-donation (compare 5 to 18).

Additional alkyl groups. Copper catalysts are often used to 50 assist the alkylation of unsaturated species. The formation of $\pi$ alkene- $\left[\mathrm{CuL}_{\mathrm{n}}(\mathrm{Alkyl})\right]$ complexes has been established as reactive intermediate $^{[9]}$ and complexes like 15, 25-26 can illustrate situations in a number of experiments. ${ }^{[37]}$ The effect of the alkyl group on the electronic properties of the $\pi$ ethylene complex was 55 thus studied with different ancillary ligands.

The alkyl group (modelled by $\mathrm{CH}_{3}$ ) was thus added to $\left[\mathrm{CuL}_{\mathrm{n}}\left(\mathrm{C}_{2} \mathrm{H}_{4}\right)\right]$ in which $\mathrm{L}$ is either a monodentate $(\mathrm{n}=1)(\mathbf{1 0}$ to $22,[2,3]$ to $[13,14])$ or a bidentate ligand $(n=2)(6$ to 15,18 to $\mathbf{2 4},[\mathbf{1 6}, \mathbf{1 7}]$ to $[\mathbf{2 5}, \mathbf{2 6}]$ ) (see values and notations in Fig 5). For $n$ $60=1$, the methyl group added to $\left[\mathrm{CuL}\left(\mathrm{C}_{2} \mathrm{H}_{4}\right)\right]$ increases significantly the back-donation by about 0.4 e ([2-3] to [13-14] and $\mathbf{1 0}$ to 22 in Fig. 5). This can be associated to the favourable orbital arrangement already presented in Figure 4. Upon coordination of $\mathrm{CH}_{3}$, the d orbital involved in back-donation goes ${ }_{65}$ from being non-bonded with a single ligand to be $\sigma$-antibonding with the $2 \mathrm{X}$ ligands. The energy increase associated to this antibonding interaction is especially efficient as two very good donor ligands $\left(\mathrm{CH}_{3}\right.$ and $\left.\mathrm{NHC}\right)$ are concerned.

The situation is different when the methyl group is added to a 70 complex, which has already two ancillary ligands $(\mathrm{n}=2)$. In this case, the 4-coordinated complex (counting always ethylene as a single ligand) takes the shape of a trigonal pyramid. The $\mathrm{CH}_{3}$, the strongest electron-donor, is in the basal plane and the weakest is at the apical position, as described in the Geometries Section. The 75 apical ligand, whose distance to $\mathrm{Cu}$ is rather long, has no overlap with the d orbital that is involved in the back-donation and its influence is thus indirect (Fig. 5). The increase in back-donation is thus essentially associated to the exchange of the weak donor by a better one $\left(\mathrm{CH}_{3}\right)$ and thus significantly smaller $(<0.11 \mathrm{e})$ 80 than the direct effect seen in the monodentate case.

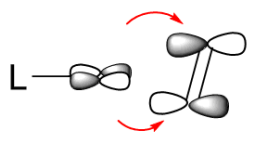

2-3 0.136 e 100.197 e

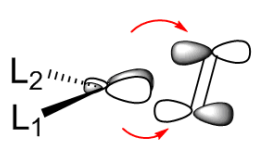

$6 \quad 0.254 \mathrm{e}$

$18 \quad 0.291 \mathrm{e}$

16-17 0.420 e
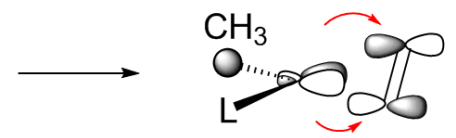

13-14 0.481 e 220.652 e

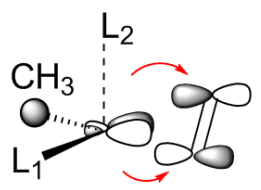

$15 \quad 0.361 \mathrm{e}$

$240.386 \mathrm{e}$ 25-26 0.451 e
Fig. 5 Effect of additional alkyl group on the back-donation: in the case of monodentate $(\mathrm{Me}(\mathbf{1 0}$ and $\mathbf{2 2})$ and NHC $([\mathbf{2 , 3}]$ and $[\mathbf{1 3}, \mathbf{1 4}]))$ and bidentate ligands (BINAP, $(\mathbf{6}, 15)$, DiPPAM, $(\mathbf{1 8}, \mathbf{2 4})$ alkoxy-NHC $[\mathbf{1 6 , 1 7}]$ and $85[\mathbf{2 5 , 2 6}])$. The $[\mathrm{a}, \mathrm{b}]$ notation refers to the average values for the two complexes.

\section{Conclusions}

In this article, we considered a set of ethylene complexes that are representative of possible intermediates in the reaction of 90 alkylation of olefin catalyzed by $\mathrm{Cu}^{(\mathrm{I})}$ complexes. The set included model species similar to those that could occur in the experiments. Cationic, neutral and anionic complexes with ligands of variable donor strength and denticity were considered. Geometry optimization shows how the ethylene is oriented 
relative to the ancillary ligands. For $\left[\mathrm{CuL}\left(\mathrm{C}_{2} \mathrm{H}_{4}\right)\right]^{\mathrm{q}}$, the ethylene ligand is trans to $\mathrm{L}$. For $\left[\mathrm{Cu}(\mathrm{L})_{2}\left(\mathrm{C}_{2} \mathrm{H}_{4}\right)\right]$ a planar structure is obtained. This can viewed as a 4-coordinated $\mathrm{d}^{8}$ square planar complex in which the olefin has been reduced as $\mathrm{X}_{2}$ ligand $5\left(\left(\mathrm{C}_{2} \mathrm{H}_{4}\right)^{2-}\right)$ and $\mathrm{Cu}^{(\mathrm{I})}$ oxidized to $\mathrm{Cu}^{(\mathrm{III})}$. Nevertheless, the computational analyses with $\mathrm{NBO}$ and CDA of the electronic structure of these complexes indicates that ethylene is bonded as a donor-acceptor ligand to $\mathrm{a} \mathrm{d}^{10} \mathrm{Cu}^{(\mathrm{I})}$ metal in all cases. In no case these complexes appear as $\mathrm{Cu}^{\text {(III) }}$ metallacyclopropane. The 10 amount of donation and especially back-donation depends the nature of the ancillary ligands and most on the coordination of the complex determined by the number of ancillary ligands. In particular, the amount of back-donation in an ethylene complex with one ancillary ligand to form a linear $\left[\mathrm{CuL}\left(\mathrm{C}_{2} \mathrm{H}_{4}\right)\right]$ complex, 15 is modest even for ligands that are good electron donors. It is enhanced by the presence of lone pairs on the ancillary ligands so that alkoxy groups behave as a better donor than alkyl groups. With two ancillary ligands, the ethylene complex has a trigonal planar geometry, considering the ethylene as a single ligand. The 20 back-donation is considerably larger with two ancillary ligands compared to one. It is controlled by the traditional trans influence so that an alkyl is a better donor than an alkoxy ligand. For three ancillary ligands, the ethylene complex is a trigonal pyramid with the weakest donor at the apical site. Calculations reveal that the 25 back-donation in the trigonal pyramid is similar to that in the trigonal planar complex since the apical ligand does not interact with the d orbital involved in the back-donation. This information can be of importance to understand the behaviour of copper catalysts in the alkylation of unsaturated ligands.

30

\section{Computational details}

The calculations were carried out with the Gaussian09 package, ${ }^{[38]}$ using the Density Functional Theory (DFT) with the exchange-correlation functional of Perdew and Wang, PW91. ${ }^{[39]}$

${ }_{35} \mathrm{Cu}$ was represented with a quasi-Relativistic Effective Pseudopotential (RECP) from Stuttgart group ${ }^{[40]}$ and the associated basis set augmented by an $\mathrm{f}$ polarization function. ${ }^{[41]}$ A $6-31++\mathrm{G}(\mathrm{d}, \mathrm{p})$ basis set was used for all other atoms $(\mathrm{H}, \mathrm{C}, \mathrm{N}, \mathrm{O}, \mathrm{F}, \mathrm{P}, \mathrm{Cl}$, $\mathrm{Br}) .{ }^{[42]}$ The geometry optimizations were performed without any 40 constraint and the nature of the minima were verified by analytical calculations of frequencies.

To select the functional, test calculations were carried out using $\left[\mathrm{Cu}(\text { tme })\left(\mathrm{C}_{2} \mathrm{H}_{4}\right)\right]^{+}$whose solid state structure is known. ${ }^{[43]}$ Calculations carried out with PW91, ${ }^{[39]}$ B3LYP, ${ }^{[44]}$ ${ }_{45}$ B3PW91, ${ }^{[44 a, 45]}$ M06, ${ }^{[46]}$ and $\mathrm{PBE}^{[47]}$ indicated that PW91 gave the best compromise for all geometrical parameters (Supporting Information).

The bonding interaction between the metal moiety $\left[\mathrm{CuL}_{n}\right]$ and the ethylene fragment was analyzed with the bond dissociation 50 energy $\mathrm{D}_{\mathrm{e}}$ defining as the energy difference between the complex $\left[\mathrm{CuL}_{\mathrm{n}}\left(\mathrm{C}_{2} \mathrm{H}_{4}\right)\right]$ and the two monomers $\left[\mathrm{CuL}_{\mathrm{n}}\right]$ and $\mathrm{C}_{2} \mathrm{H}_{4}$ separated at infinite distance in their electronic ground states and optimized geometry. The deformation energy Def is determined for each fragment, $\left[\mathrm{CuL}_{\mathrm{n}}\right]$ and $\mathrm{C}_{2} \mathrm{H}_{4}$, as the energy difference between ${ }_{55}$ their equilibrium structure and the geometries they have in the complex $\left[\mathrm{CuL}_{\mathrm{n}}\left(\mathrm{C}_{2} \mathrm{H}_{4}\right]\right.$. The interaction energy (IE) is the difference between the energy of the complex and the energies of the two fragments at the geometry they have within the complex. The bond dissociation energy, $\mathrm{D}_{\mathrm{e}}$, is the sum of IE and Def. For ${ }_{60}$ complexes $\mathbf{1}$ and 27, for which one of the fragment is a $\mathrm{Cu}^{+}$ cation, MP2 - BSSE corrected values for IE were used and reported in Table 1 and not the De values, which we believe to be strongly biased.

The Natural Population Analysis (NPA) was used to evaluate the ${ }_{65}$ natural atomic charge of $\mathrm{Cu} .{ }^{[48]}$ The electronic properties of $\mathrm{C}=\mathrm{C}$ bonding in the complexes were analyzed using the Natural Bond Orbital (NBO) method ${ }^{[49]}$ which allows a description of the bonding in terms of Ethylene $\rightarrow \mathrm{Cu} \pi$-donation and $\mathrm{Cu} \rightarrow$ Ethylene $\pi$-back-donation. All calculations were carried out with ${ }_{70} \mathrm{NBO}-06$ package ${ }^{[50]}$ on the DFT optimized geometry.

Charge Decomposition Analysis (CDA) was used as described in the literature ${ }^{[51]}$ considering that $\left[\mathrm{CuL}_{n}\left(\mathrm{C}_{2} \mathrm{H}_{4}\right)\right]$ is formed of the union of two fragments $\left[\mathrm{CuL}_{n}\right]$ and $\mathrm{C}_{2} \mathrm{H}_{4}$ (in the geometry they have in the complex). The wave function of a complex ${ }_{75}\left[\mathrm{CuL}_{\mathrm{n}}\left(\mathrm{C}_{2} \mathrm{H}_{4}\right)\right]$ is expressed as a linear combination of the fragment molecular orbitals (MOs) of the ligand $\mathrm{C}_{2} \mathrm{H}_{4}$ and the metal fragment $\left[\mathrm{CuL}_{n}\right]$. The orbital contributions of the fragments to wave function of the complex are divided into four parts: (i) mixing of the occupied MOs of $\mathrm{C}_{2} \mathrm{H}_{4}$ and the unoccupied MOs of $80\left[\mathrm{CuL}_{\mathrm{n}}\right]$ (donation d); (ii) mixing of the unoccupied MOs of $\mathrm{C}_{2} \mathrm{H}_{4}$ and the occupied MOs of $\left[\mathrm{CuL}_{n}\right]$ (back-donation b); (iii) mixing of the occupied MOs of $\mathrm{C}_{2} \mathrm{H}_{4}$ and of $\left[\mathrm{CuL}_{n}\right]$ (repulsive polarization $\mathrm{r}$ ) and (iv) mixing of the unoccupied MOs of $\mathrm{C}_{2} \mathrm{H}_{4}$ and of $\left[\mathrm{CuL}_{\mathrm{n}}\right]$ (residual term $\left.\Delta\right) .{ }^{[52]}$ This last term must to be $\approx 0$ 85 for donor-acceptor complexes otherwise the interaction between ethylene and $\left[\mathrm{CuL}_{n}\right]$ is described as a covalent interaction. Calculations of CDA used MP2 ${ }^{[53]}$ level with the 6-31G(d,p) basis set for all atom. ${ }^{[42]} \mathrm{Cu}$ was represented at the same level as in the DFT calculations. All structures were optimized at the MP2 90 level and found to be very similar to that obtained with PW91.

\section{Acknowledgments}

This works was supported by the Agence Nationale de la Recherche (SCATE grant no. ANR 12-BS07-0009-01).

95 Notes and references

${ }^{a}$ Sorbonne Universités, UPMC Univ Paris 06, UMR 7616, Laboratoire de Chimie Théorique, F-75005, Paris, France. E-mail:

halbert@lct.jussieu.fr

${ }^{b}$ CNRS, UMR 7616, Laboratoire de Chimie Théorique, F-75005, Paris, 100 France

$\dagger$ Electronic Supplementary Information (ESI) available: Additional FIGURES showing various correlations. Cartesian coordinates and energies ( $\mathrm{E}$ in a. u.) of all reported structures. See DOI: $10.1039 / \mathrm{b} 000000 \mathrm{x} /$

105

[1] N. Krause, Modern Organocopper Chemistry, Wiley-VCH, Weinheim, Germany, 2002.

[2] D. S. Surry and S. L. Buchwald, Chem. Sci., 2010, 1, 13-31.

[3] Z. Rappoport and I. Marek, The Chemistry of Organocopper 110 Coumpounds: Part 1 and Part 2, Wiley: Chichester, 2009.

[4] N. Yoshikai and E. Nakamura, Chem. Rev., 2012, 112, 2339-2372.

[5] see for instance: a) B. F. Straub, F. Eisenträger and P. Hofmann, Chem. Commun., 1999, 2507-2508. b) G. Pampaloni, R. Peloso, C. Graiff, and A. Tiripicchio, Organometallics, 2005, 26, 819-825. c) M. J. Bainbridge, J. R. Lindsay Smith and P. H. Walton, Dalton Trans., 2009, 40, 3143-3152. d) P. O. Oguadinma and F. Schaper, Organometallics, 2009, 28, 6721-6731. e) C. Martín, J. M. Muñoz- 
Molina, A. Locati, E. Alvarez, F. Maseras, T. R. Belderrain and P. J. Pérez, Organometallics, 2010, 29, 3481-3489.

[6] a) J. S. Dewar, Bull. Soc. Chim. Fr., 1951, 18, C71-C79. b) J. Chatt and L. A. Duncanson, J. Chem. Soc., 1953, 2939-2947. c) J. Chatt, L. A. Duncanson and L. M. Venanzi, J. Chem. Soc., 1955, 4456-4460.

[7] T. A. Albright, R. Hoffmann, J. C. Thibeault and D. L. J. Thorn, J. Am. Chem. Soc., 1979, 101, 3801-3812.

[8] J. F. Hartwig, Organotransition Metal Chemistry: From Principles to Catalysis; University Science Books: Herndon, VA, 2010.

10 [9] a) N. Krause, R. Wagner and A. Gerold, J. Am. Soc. Chem., 1994, 116, 381-382. b) N. Krause and A. Gerold, Angew. Chem., 1997, 109, 194-213. c) N. Krause and A. Gerold, Angew. Chem. Int. Ed., 1997, 36, 186-204. d) J. Canisius, A. Gerold and N. Krause, Angew. Chem. Int. Ed., 1999, 38, 1644-1646.

15 [10] a) E. Nakamura, S. Mori and K. Morokuma, J. Am. Soc. Chem., 1998, 120, 8273-8274. b) S. Mori, E. Nakamura and K. Morokuma, J. Am. Soc. Chem., 2000, 122, 7294-7307. c) S. Mori, M. Uerdingen, N. Krause and K. Morokuma, Angew. Chem., 2005, 117, 4795-4798. d) S. Mori, M. Uerdingen, N. Krause and K. Morokuma, Angew. Chem. Int. Ed., 2005, 44, 4715-4719.

[11] M. S. Nechaev, V. M. Rayon and G. Frenking, J. Phys. Chem. A, 2004, 108, 3134-3142.

[12] G. Sánchez-Sanz, I. Alkorta, J. Elguero, M. Yáñez and O. Mó, Phys. Chem. Chem. Phys., 2012, 14, 11468-11477.

25 [13] N. C. Pernicone, J. B. Geri and J. T.York, Theor. Chem. Acc., 2012, 131, 1-12.

[14] J. B. Geri, N. C. Pernicone and J. T. York, Polyhedron, 2013, 52, 207-215.

[15] L. Perrin, E. Clot, O. Eisenstein, J. Loch and R. H. Crabtree, Inorg. Chem., 2001, 40, 5806-5811.

[16] R. A. Kelly III, H. Clavier, S. Giudice, N. M. Scott, E. D. Stevens, J. Bordner, I. Samardjiev, C. D. Hoff, L. Cavallo and S. P. Nolan, Organometallics, 2008, 27, 202-210.

[17] N. Fey, M. F. Haddow, J. N. Harvey, C. L. McMullin and A. G. Orpen, Dalton Trans., 2009, 8183-8196.

[18] N. Fey, Dalton Trans., 2010, 39, 296-310.

[19] J. Jover, N. Fey, J. N. Harvey, G. C. Lloyd-Jones, A. G. Orpen, G. J. J. Owen-Smtith, P. Murray, D. R. J. Hose, R. Osborne, and M. Purdie, Organometallics, 2010, 29, 6245-6258.

40 [20] For a recent overview see: M. N. Hopkinson, C. Richter, M. Schedler, F. Glorius, Nature, 2014, 510, 485-496.

[21] a) D. Martin, S. Kehrli, M. d'Augustin, H. Clavier, M. Mauduit and A. Alexakis, J. Am. Soc. Chem., 2006, 128, 8416-8417. b) J. Wencel, M. Mauduit, H. Hénon, S. Kehrli and A. Alexakis, Aldrichimica

45 Acta, 2009, 42, 43-50. c) S. Kehrli, D. Martin, D. Rix, M. Mauduit and A. Alexakis, Chem. Eur. J., 2010, 16, 9890-9904.

[22] a) M. Tissot, D. Poggiali, H. Hénon, D. Müller, L. Guénée, M. Mauduit and A. Alexakis, Chem. Eur. J., 2012, 18, 8731-8747. b) N. Germain, M. Magrez, S. Kehrli, M. Mauduit and A. Alexakis, Eur. J.

$50 \quad$ Org. Chem., 2012, 2012, 5301-5306. c) M. Magrez, Y. Le Guen, O. Baslé, C. Crévisy and M. Mauduit, Chem. Eur. J., 2013, 19, 11991203.

[23] S. Cai, J. F. Payack, S. R. Bender, D. L. Hughes, T. R. Verhoeven and P. J. Reider, Org. Synth., 1999, 76, 6-11.

55 [24] J. Wencel, S. Rix, T. Jennequin, S. Labat, C. Crévisy and M. Mauduit, Tetrahedron: Asymmetry, 2008, 19, 1804-1809.

[25] a) T. Ziegler and A. Rauk, Inorg. Chem., 1979, 18, 1558-1565. b) M. Merchan, R. Gonzalez-Luque, I. Nebot-Gill and F. Tomas, Chem. Phys. Lett., 1984, 112, 412-416. c) M. Sodupe, M.; C. W.

60 Bauschlicher Jr, S. R. Langhoff and H. Partridge, J. Phys. Chem., 1992, 96, 2118-2122. d) M. Böhme, T. Wagener and G. Frenking, $J$. Organomet. Chem., 1996, 520, 31-43. e) R. H. Hertwig, W. Koch, D. Schröder, H. Schwarz, J. Hrusak and P. Schwerdtfeger, J. Phys. Chem., 1996, 100, 12253-12260.

${ }_{65}[26]$ S. L. Stephens, S. R. Bittner, V. A. Mikhailov, W. Mizukami, D. P. Tew, N. R. Walker and A. C. Legon, Inorg. Chem., 2014, 53, 1072210730 .

[27] K. Morokuma and W. T. Borden, J. Am. Chem. Soc., 1991, 113, 1912-1914.

70 [28] J. Uddin, S. Dapprich and G. Frenking, Organometallics, 1999, 18, 457-465.
[29] S. Mori, A. Hirai, M. Nakamura and E. Nakamura, Tetrahedron, 2000, 56, 2805-2809.

[30] J. P. Snyder, Angew. Chem. Int. Ed. Engl., 1995, 34, 80-81.

75 [31] a) G. Parkin, J. Chem. Educ., 2006, 83, 791-799; b) M. Kaupp, Angew. Chem. Int. Ed., 1995, 34, 986-986; c) J. P. Snyder, Angew. Chem. Int. Ed., 1995, 34, 986-987.

[32] F. Weinhold and C. R. Landis, Valency and Bonding, Cambridge University Press: Cambridge, 2005.

80 [33] J. K. Bera, A. G. Samuelson and J. Chandrasekhar, Organometallics, 1998, 17, 4136-4145.

[34] T. A. Albright, J. K. Burdett and M.-H. Whangbo, Orbitals Interactions in Chemistry; Wiley, New York, N.Y. 1985, $\left(1^{\text {st }}\right.$ ed) and 2013 ( $2^{\text {nd }}$ ed $)$.

85 [35] K. G. Caulton, New J. Chem., 1994, 18, 25-41.

[36] D. J. Nelson and S. P. Nolan, Chem. Soc. Rev., 2013, 42, 6723-6753.

[37] a) J. Wencel-Delord, A. Alexakis, C. Crévisy and M. Mauduit, Org. Lett., 2010, 12, 4335-4337. b) M. Magrez-Chiquet, M. S. T. Morin, J. Wencel-Delord, S. Drissi Amraoui, O. Baslé, A. Alexakis, C. Crévisy 90 and M. Mauduit, Chem. Eur. J., 2013, 19, 13663-13667.

[38] Gaussian 09, Revision D.01, M. J. Frisch, G. W. Trucks, H. B. Schlegel, G. E. Scuseria, M. A. Robb, J. R. Cheeseman, G. Scalmani, V. Barone, B. Mennucci, G. A. Petersson, H. Nakatsuji, M. Caricato, X. Li, H. P. Hratchian, A. F. Izmaylov, J. Bloino, G. Zheng, J. L. Sonnenberg, M. Hada, M. Ehara, K. Toyota, R. Fukuda, J. Hasegawa, M. Ishida, T. Nakajima, Y. Honda, O. Kitao, H. Nakai, T. Vreven, J. A. Montgomery, Jr., J. E. Peralta, F. Ogliaro, M. Bearpark, J. J. Heyd, E. Brothers, K. N. Kudin, V. N. Staroverov, R. Kobayashi, J. Normand, K. Raghavachari, A. Rendell, J. C. Burant, S. S. Iyengar, J. Tomasi, M. Cossi, N. Rega, J. M. Millam, M. Klene, J. E. Knox, J. B. Cross, V. Bakken, C. Adamo, J. Jaramillo, R. Gomperts, R. E. Stratmann, O. Yazyev, A. J. Austin, R. Cammi, C. Pomelli, J. W. Ochterski, R. L. Martin, K. Morokuma, V. G. Zakrzewski, G. A. Voth, P. Salvador, J. J. Dannenberg, S. Dapprich, A. D. Daniels, Ö. Farkas, J. B. Foresman, J. V. Ortiz, J. Cioslowski, and D. J. Fox, Gaussian, Inc., Wallingford CT, 2009.

[39] J. P. Perdew, K. Burke and Y. Wang, Phys. Rev. B, 1996, 54, 1653316539.

[40] D. Andrae, U. Häussermann, M. Dolg, H. Stoll and H. Preuss, Theor. Chim. Acta, 1990, 77, 123-141.

[41] A. W. Ehlers, M. Böhme, S. Dapprich, A. Gobbi, A. Höllwarth, K. F. Köhler, R. Stegmann, A. Veldkamp and G. Frenking, Chem. Phys. Lett., 1993, 208, 111-114.

[42] a) W. J. Hehre, R. Ditchfield and J. A. Pople, J. Chem. Phys., 1972, 115 56, 2257-2261. b) M. M. Francl, W. J. Pietro, W. J. Hehre, J. S. Binkley, M. S. Gordon, D. J. DeFrees and J. A. Pople, J. Chem. Phys., 1982, 77, 3654-3665.

[43] Y. Suenaga, L. P. Ping Wu, T. Kuroda-sowa, M. Munakata and M. Maekawa, Polyhedron, 1997, 16, 67-70.

120 [44] a) A. D. Becke, J. Chem. Phys., 1993, 98, 5648-5652. b) P. J. Stephens, F. J. Devlin, C. F. Chabalowski and M. J. Frisch, J. Phys. Chem., 1994, 98, 11623-11627.

[45] J. P. Perdew and Y. Wang, Phys. Rev. B, 1992, 45, 13244-13249.

[46] Y. Zhao and D. G. Truhlar, Theor. Chem. Acc., 2008, 120, 215-241.

125 [47] J. P. Perdew, K. Burke and M. Ernzerhof, Phys. Rev. Lett., 1996, 77, 3865-3868.

[48] A. E. Reed, L. A. Curtiss and F. Weinhold, Chem. Rev., 1988, 88, 899-926.

[49] A. E. Reed and F. Weinhold, J. Chem. Phys., 1985, 83, 1736-1740.

130 [50] NBO Version 6.0, E. D. Glendening, J. K. Badenhoop, A. E. Reed, J. E. Carpenter, J. A. Bohmann, C. M. Morales, C. R. Landis and F. Weinhold, Theoretical Chemistry Institut, University of Wisconsin, Madison, WI, USA 2013, http://nbo6.chem.wisc.edu/.

[51] S. Dapprich and G. Frenking, J. Phys. Chem., 1995, 99, 9352-9362.

135 [52] G. Frenking, M. Solà and S. F. Vyboishchikov, J. Organomet. Chem., 2005, 690, 6178-6204.

[53] M. Head-Gordon, J. A. Pople and M. J. Frisch, Chem. Phys. Lett., 1988, 153, 503-506.

\section{TOC}

${ }_{140}$ Structural and electronic calculations on a ligand database are

used to quantify the influence of the ancillary ligands and 
coordination mode on the electronic structure of $\mathrm{Cu}(\mathrm{I})$ ethylene complexes.

$\mathrm{n}=0$ to 3

$q=+1,0,-1$
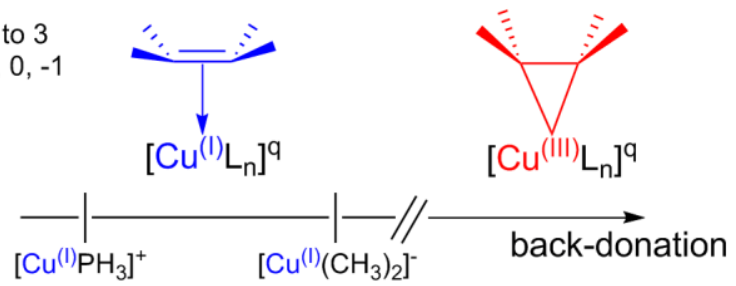

15

Table 1: Selected $\left(\mathrm{C}=\mathrm{C}\right.$ and $\left\langle\mathrm{Cu}-\mathrm{C}>\right.$ ) bond distances $(\AA)$, <odp $>$ angles $\left({ }^{\circ}\right)$, bond dissociation $\left(\mathrm{D}_{\mathrm{e}}\right)$, deformation $(\mathrm{Def})$ and interaction $(\mathrm{IE})$ energies (kcal/mol), natural atomic charge $\left(\mathrm{q}_{\mathrm{Cu}}\right)$ and electron occupancies of $\mathrm{C}_{2} \mathrm{H}_{4}\left(\pi\right.$ and $\left.\pi^{*}\right)$ from NBO analysis (n refers to denticity and $\mathrm{q}$ to formal charge of complexes). 


\begin{tabular}{|c|c|c|c|c|c|c|c|c|c|c|c|}
\hline Entry & $\mathrm{q}$ & $\mathrm{n}$ & $\mathrm{C}=\mathrm{C}$ & $\langle\mathrm{Cu}-\mathrm{C}\rangle$ & $\langle\text { opd }\rangle^{[c]}$ & $D_{e}$ & Def & IE & $\mathrm{q}_{\mathrm{Cu}}$ & $\mathrm{C}_{2} \mathrm{H}_{4}(\pi)$ & $\mathrm{C}_{2} \mathrm{H}_{4}\left(\pi^{*}\right)$ \\
\hline Free ethylene & & & 1.341 & & 180.0 & & & & & 1.996 & 0.003 \\
\hline 1 & 1 & 0 & 1.395 & 2.0445 & 167.3 & & & $-43.7^{[\mathrm{a}]}$ & 0.871 & 1.733 & 0.135 \\
\hline 2 & 1 & 1 & 1.377 & 2.089 & 169.2 & 39.4 & 3.7 & -43.1 & 0.659 & 1.825 & 0.143 \\
\hline 3 & 1 & 1 & 1.375 & 2.099 & 169.4 & 38.2 & 3.6 & -41.8 & 0.657 & 1.828 & 0.128 \\
\hline 4 & 1 & 2 & 1.383 & 2.111 & 166.0 & 19.1 & 18.7 & -37.8 & 0.696 & 1.848 & 0.215 \\
\hline 5 & 1 & 1 & 1.376 & 2.1055 & 169.8 & 43.3 & 3.6 & -47.0 & 0.638 & 1.806 & 0.103 \\
\hline 6 & 1 & 2 & 1.387 & 2.081 & 165.6 & 28.5 & 9.7 & -38.2 & 0.707 & 1.845 & 0.254 \\
\hline 7 & 0 & 1 & 1.392 & 2.004 & 165.7 & 45.6 & 4.7 & -50.2 & 0.893 & 1.828 & 0.267 \\
\hline 8 & 0 & 1 & 1.388 & 2.029 & 167.1 & 40.3 & 4.2 & -44.5 & 0.754 & 1.833 & 0.238 \\
\hline 9 & 0 & 1 & 1.387 & 2.035 & 167.3 & 38.9 & 4.1 & -43 & 0.711 & 1.836 & 0.236 \\
\hline 10 & 0 & 1 & 1.377 & 2.0935 & 169.6 & 24.0 & 3.8 & -27.8 & 0.623 & 1.863 & 0.197 \\
\hline 11 & 0 & 1 & 1.398 & 2.0005 & 164.4 & 41.4 & 7.0 & -48.4 & 0.859 & 1.825 & 0.334 \\
\hline 12 & 0 & 1 & 1.379 & 2.069 & 169.4 & 35.6 & 3.6 & -39.1 & 0.683 & 1.850 & 0.178 \\
\hline 13 & 0 & 2 & 1.409 & 2.041 & 161.0 & 4.1 & 33.5 & -37.6 & 0.870 & 1.868 & 0.480 \\
\hline 14 & 0 & 2 & 1.409 & 2.044 & 160.5 & 3.0 & 34.2 & -37.2 & 0.864 & 1.872 & 0.482 \\
\hline 15 & 0 & 3 & 1.394 & 2.1165 & 164.6 & 9.1 & 18.5 & -27.6 & 0.805 & 1.885 & 0.361 \\
\hline 16 & 0 & 2 & 1.404 & 2.0205 & 162.4 & 28.6 & 14.5 & -43.1 & 0.944 & 1.870 & 0.419 \\
\hline 17 & 0 & 2 & 1.404 & 2.0185 & 162.3 & 29.5 & 14.2 & -43.7 & 0.941 & 1.870 & 0.420 \\
\hline 18 & 0 & 3 & 1.390 & 2.0615 & 166.7 & 10.6 & 22.5 & -33.1 & 0.880 & 1.873 & 0.291 \\
\hline 19 & -1 & 2 & 1.413 & 1.982 & 163.1 & 3.9 & 36.9 & -40.8 & 1.097 & 1.890 & 0.471 \\
\hline 20 & -1 & 2 & 1.397 & 2.040 & 167.9 & 3.2 & 25.4 & -28.6 & 0.875 & 1.897 & 0.367 \\
\hline 21 & -1 & 2 & 1.394 & 2.056 & 168.5 & 4.0 & 22.8 & -26.8 & 0.809 & 1.898 & 0.352 \\
\hline 22 & -1 & 2 & 1.428 & 2.0185 & 158.3 & 1.6 & 42.7 & -44.3 & 0.893 & 1.889 & 0.652 \\
\hline 23 & -1 & 2 & 1.416 & 1.985 & 161.0 & 4.0 & 39.4 & -43.4 & 1.037 & 1.883 & 0.523 \\
\hline 24 & -1 & 3 & 1.396 & 2.1045 & 166.6 & 3.9 & 22.1 & -26.0 & 0.890 & 1.898 & 0.386 \\
\hline 25 & -1 & 3 & 1.403 & 2.076 & 165.3 & 8.6 & 23.2 & -31.7 & 0.970 & 1.899 & 0.448 \\
\hline 26 & -1 & 3 & 1.403 & 2.0765 & 164.6 & 5.5 & 26.3 & -31.8 & 0.960 & 1.902 & 0.455 \\
\hline $\begin{array}{c}\text { Strained } C=C \\
\mathbf{2 7}\end{array}$ & 1 & 0 & $\begin{array}{l}1.375 \\
1.453\end{array}$ & 2.015 & $\begin{array}{l}121.3^{[b]} \\
120.0^{[b]}\end{array}$ & & & $-71.1^{[\mathrm{a}]}$ & 0.779 & $\begin{array}{l}1.911 \\
1.604\end{array}$ & $\begin{array}{l}0.138 \\
0.392\end{array}$ \\
\hline
\end{tabular}

[a] MP2-BSSE corrected values, see Computational Details. [b] C-C-C angles in degrees. [c] out-of-plane displacement, evaluated as the average of the $\mathrm{HHC}=\mathrm{C}$ angle at the two ends of the ethylene. 